\title{
12. Demand Sharing, Nutrition and Warlpiri Health: The social and economic strategies of food choice
}

\author{
Eirik Saethre \\ University of Hawai'i at Mānoa
}

Throughout his long and productive career, Nicolas Peterson has exerted a profound influence on Australian anthropology, exploring a wide range of theoretically engaging issues. In this chapter, I focus on Peterson's insights regarding the ways in which social norms intersect with the financial constraints of unemployment benefits and other government assistance packages. A central theme for Peterson is reciprocity (see also Altman, Gomes, Kwok and Martin, this volume). On one hand, the Australian Government has distributed food and cash to Aboriginal people. On the other hand, Aboriginal individuals exchange resources with one another. In each instance, exchange acts as a way of building relationships between individuals and groups. Building upon Peterson's work, I examine the way in which past and present exchanges of food structure the continuing high rates of Aboriginal malnutrition and ill health in the Northern Territory.

With life expectancy for Aboriginal people in the Northern Territory approximately 20 years less than that of non-Aboriginal Territorians, research estimates that 77 per cent of this gap can be attributed to the high rate of noncommunicable chronic and lifestyle diseases among Aboriginal Australians (Northern Territory Department of Health and Community Services 2003: 24; Zhao and Dempsey 2006). ${ }^{1}$ Chronic diseases are caused and exacerbated by high rates of obesity and malnutrition, which are in turn the result of an excessive consumption of sugar and fat. ${ }^{2}$ While health education campaigns have imparted a good understanding of nutrition to Aboriginal people, this has

\footnotetext{
1 Approximately 13.4 per cent of Aboriginal people living in the Northern Territory have Type II diabetes, while 11.5 per cent suffer from hypertension (Zhao et al. 2008). Almost 60 per cent of the Aboriginal population will have at least one chronic condition by the age of thirty-five to forty-four years, which will require continual medical treatment, often with multiple drugs, for the rest of their lives (Hoy et al. 2007: 181). 2 The incidence of obesity in the Northern Territory has been recorded as high as 38 per cent in some areas (Hoy et al. 2007), while malnutrition continues to be a persistent problem, particularly among children (Russell et al. 2004). Beef, white flour and sugar provide half of the energy intake of an average Aboriginal community in the Northern Territory (Northern Territory Department of Health and Community Services 1995: 5). Forty-five per cent of fat intake is attributed to the consumption of fatty meats while 60 per cent of sugar intake is derived from white sugar, amounting to approximately 38 teaspoons per person per day (Harrison 1991:127).
} 
not resulted in a significant change in eating habits. In 1996, when I first began conducting fieldwork in Lajamanu, a Warlpiri community in the Northern Territory, I was struck by the frequency with which people complained about the poor nutritional content of food served by the local takeaway only to find them purchasing lunch there later the same day (for other research relating to Warlpiri people, see Curran and Morton, this volume). On a recent visit in 2009, the same pattern was occurring. To understand why rates of nutrition have not improved, food acquisition and consumption must be situated within the social and economic environment of remote Aboriginal communities, such as Lajamanu.

I begin by examining the strategy of rationing and the subsequent transition to a cash economy and welfare payments. Building upon Peterson's (1998) critique of Paine's (1977) notion of 'welfare colonialism' (for discussion of this concept, see also Altman, Kwok and Martin, this volume), I investigate the way in which a reliance on government assistance and the high cost of food in remote Aboriginal communities structures when, where and what kind of food is purchased and consumed. After an ethnographic examination of the way in which Warlpiri people patronise Lajamanu's shop and takeaway, I argue that food consumption in Lajamanu is further influenced by what Peterson (1993) refers to as demand sharing: reciprocity via direct request rather than unsolicited giving. Following Peterson (1999), I assert that sharing food acts as a tool to build and maintain social relationships. Consequently, the food choices of Lajamanu residentsand high rates of chronic illness - are underpinned by economic and social strategies that often take priority over knowledge of nutrition and disease.

\section{From Rations to Welfare}

The availability of food and water has historically structured social relations between the Indigenous people of the Northern Territory, as well as their interactions with non-Aboriginal explorers and settlers. As pastoralists settled in central Australia, conflicts over water, land and cattle predation typified relations between Aboriginal and non-Aboriginal people (Peterson et al. 1978). In an effort to secure their safety and livelihoods, pastoralists sought a method through which relationships with Aboriginal people could be managed beneficially (May 1994; Wright 1981). While force through the use of weaponry was common, an alternative strategy was to socially engage Aboriginal people through the distribution of materials, including food. Dried tea-leaves, white flour, sugar and preserved meat were rationed throughout the Northern Territory in towns, missions and cattle stations. 
In his examination of rationing in the Northern Territory, Rowse (1998) notes that government officials anticipated the material and social exchange of rations having a profound impact on the economy and lifestyle of Aboriginal people. It was hoped that rations would encourage Aboriginal people to sell their labour to cattle stations, which were in constant need of a cheap workforce. Rations were intended to encourage not only economic changes, but also social ones. Pursuing a policy of assimilation, the Australian Government attempted to use rationing as a strategy through which white values, manners and eating habits would be imparted to the Aboriginal population (see Martin, this volume, for a critique underlying such assumptions). It was hoped that as a consequence of the experiences of employment at a cattle station, queuing up for a ration allotment, and being taught to prepare and consume the distributed food, Aboriginal people would adopt the lifestyle and values of white Australia, which included a strong work ethic, timeliness and hygiene.

The Government did not intend for rationing to be a permanent strategy. It was viewed as a vital stage in the evolution and eventual assimilation of Aboriginal people into the Australian cash economy. This process would be accomplished, in part, by the gradual introduction of cash wages. Ian Sharp (1966: 162), of the Department of Labour and National Service, wrote that the transition to 'equal wages' for Aboriginal pastoral workers would encourage 'the handling of cash wages and accepting increasingly the family responsibilities of a normal wage earner.' In 1969, rationing effectively ended with the full integration of Aboriginal Territorians into the cash economy. Initially, cash payments to unemployed individuals were limited to those who had either been previously employed or were undertaking training. But by 1973-74, unemployment benefits were made universally available to Aboriginal people. In place of rations, the state had instituted a cash-based regime of government payments to Aboriginal people-welfare.

Despite receiving cash wages, many Aboriginal people chose not to sell their labour. The introduction of unemployment benefits was motivated by a marked increase in poverty in Aboriginal communities after 1969. Rowse (1998: 180) writes:

When cash award wages, training allowances and social service benefits were introduced on settlement in 1969, the 'problem' of the ill-prepared Indigenous family began to appear prolifically in Administration files, under three themes: Were parents willing to look after their families? Did they have the dietary knowledge to do so competently? Could they afford to do so?

Administrators and government officials questioned whether Aboriginal people could now adequately 'look after' themselves. In many instances, the answer 
was 'no'. In 1970, observers noted that while Aboriginal people purchased food at the local shop or canteen immediately after receiving pay, by the end of the two-week pay cycle, spending was dramatically reduced (Rowse 1998: 181). Lack of food entailed inadequate child nutrition, which was a particular concern of government officials (Rowse 1998: 180).

Although the transition from rations to cash was intended to shift Aboriginal policy from dependency to self-determination, anthropologists have questioned whether this move has in fact occurred (cf. Martin, this volume). In 1977, Robert Paine coined the phrase 'welfare colonialism', asserting that government allocations to Indigenous peoples actually entrench social and political dependency. Welfare payments, he argues, are emblematic of larger incongruities that exist in modern relationships between industrially developed nation-states and the Indigenous minorities who inhabit them (Paine 1977). Receiving the dole represents the rights of citizenship, while, simultaneously, the state continues to control economies in Indigenous communities. Nicolas Peterson (1998) has argued for a more nuanced approach to welfare colonialism, noting that too often the everyday economic and social realities of welfare are ignored. While the state is in control of distributing monies, Indigenous agency does play a role in determining the use and redistribution of these resources. As Peterson (1999) rightly observes, welfare payments allow Aboriginal people to pursue local social and cultural activities, such as playing cards or attending ceremony, without the need to sell their labour in a capitalist market. Cash is used to reproduce and strengthen social relations. One way in which this is accomplished is through the redistribution of food purchased from the store via demand sharing.

\section{The Store}

Data suggest that between 80 (Northern Territory Department of Health and Community Services 1995: 5) and 95 per cent (Food and Nutrition Unit 1998: 1) of all food eaten in Aboriginal communities is purchased at the local store and takeaway. In Lajamanu, 'the shop' was the only source of commercial food in the community. Food could be purchased from one of three outlets that were managed as a unit and housed in a single building complex. The main store stocked the largest selection of foods as well as a modest selection of toiletries, clothes and homewares. The takeaway provided prepared meals such as chips, grilled chicken, stew, salads and sandwiches. The final option was the 'video shop', which sold a limited selection of foods after the main store closed. ${ }^{3}$

3 Further compounding the risk of ill health, more than half of the Aboriginal population of the Northern Territory smokes daily (Australian Bureau of Statistics 2006: Table 1). Like commercial foods, tobacco is purchased from the local shop and shared between individuals. 
Warlpiri people often state that food purchased from the shop contains high levels of fat, salt and sugar. Consequently, shop food is blamed for causing diabetes and other chronic illnesses. Pointing to his chest, one man commented, 'You go up to the shop and buy all that greasy food-chips, chicken wings, meat pies. All of that is rubbish. It is high in fat, and stops this one.' In contrast, any foodstuff harvested from the bush is considered to aid general health. For instance, kangaroo meat is considered to be healthier than beef, chicken or pork. Another man asserted, 'Bullock fat makes you sick but I get strong eating [kangaroo] fat.' As Warlpiri people often assert, research has shown that native meats and vegetables contain higher levels of vitamins and lower levels of fat and sugar than most foods available at the store (Latz 1995; Naughton et al. 1986; O'Dea 1985). Despite these assertions and a number of health campaigns urging Aboriginal Territorians to hunt and gather greater amounts of food, Warlpiri people continued to rely on commercial food, particularly items bought from the takeaway. These choices are not the result of a lack of nutritional awareness, but rather due to income, cost, availability and a desire to avoid excessive reciprocity.

The main store resembled many small shops across Australia. It contained a few aisles of food as well as refrigerator and freezer sections on the back and side walls. While basic foods were stocked, there was generally not a great selection. For instance, only two varieties of cheese were often available: tasty and processed. Although the Lajamanu store did not carry the same variety of items a shopper would expect to find in an urban environment, Warlpiri people consumed a relatively narrow range of food that the shop did sell. Fresh pasta and marinara sauce might have been difficult to find in Lajamanu, but instead the store sold large buckets of sugar and flour, which shoppers in Sydney would have trouble locating at their supermarket. The shop also stocked a variety of fruits and vegetables, which commonly included apples, bananas, nectarines, kiwifruit, peaches, oranges, snow peas, beans, mushrooms, potatoes, carrots, celery, lettuce, tomatoes, onions, garlic, zucchini, pumpkins, squash, broccoli and cauliflower. There was never, however, a great quantity of fresh foods, and popular items such as apples sold out quickly.

For those wishing to make healthy food choices, wholemeal bread, sugar-free cordial and low-fat milk were all available. Items containing less than $10 \mathrm{~g}$ of sugar and $7.5 \mathrm{~g}$ of fat per $100 \mathrm{~g}$ were considered healthier choices and often labelled with a yellow tag. Some of these foods included canned spaghetti, canned pineapple, canned meat and assorted dehydrated soup mixes. I was told, however, that few people choose items based on these signs. In many cases, familiarity superseded nutritional considerations. For instance, when I asked one older man why he did not eat wholegrain bread as a healthier alternative to white bread, he replied, 'White bread is what we eat. All the way back in the 
rationing days, it was what we had. It is proper food.' Growing up on a diet of meat, white bread and sugary tea has led many residents to continue to eat these foods almost exclusively, despite a range of alternatives sold at the local shop. Noting the frequency with which flour, tea, sugar and chops are consumed, Musharbash (2004: 15) writes, 'It is what Warlpiri people at Yuendumu are used to and know as staple since ration depot and communal soup kitchen times.' The era of rations continues to exert a profound influence on the food choices of Warlpiri people today.

The most popular day for shopping was when government assistance and pay cheques arrived. People crowded the store and the queues for the checkout were especially long. On one payday, I found myself in line behind Daisy, ${ }^{4}$ a thirtytwo-year-old woman, who was raising five children. Like many other women shopping for their families, she was pushing two full trolleys. Daisy explained that she was pleased to once again have money to purchase food, which was now in short supply at her home. As she checked out, I noticed that her purchases included a $10 \mathrm{~kg}$ bucket of flour, five bottles of cordial, several kilograms of meat, five loaves of bread, five tins of stew, several cans of baked beans, a few boxes of tea, a few apples, a head of cauliflower, milk powder and a tin of sugar. Her bill came to more than $\$ 300$.

Although more than three decades have passed since government distributions and pay were first received in cash, the two-week income cycle continues to determine when and how much food can be purchased. In Lajamanu, as in many Aboriginal communities (Stewart 1997: 3), there is no meal planning or budgeting from week to week. Income is used for immediate consumption, not for saving (Peterson 1991: 84). As a result, residents often live on a cycle of feast and famine. The 'feast' occurs at either pay week or benefits week, when large amounts of money are spent to buy food. After several days have passed and income has been exhausted, the 'famine' cycle begins. During this periodreferred to as 'my low week' - the primary method of obtaining much needed food is to seek assistance from family members. Through demand sharing, Warlpiri people are accustomed to distributing food regularly. If an individual is hungry and sees a relative with food, it is common practice to request a share. It is generally considered rude to refuse a request if in possession of the food item being demanded.

During 'my low week', residents often wait outside the store hoping to spot a kinsman leaving with food. Eager relatives are then capable of appropriating and consuming as much as half of the purchase. For instance, as I was helping Daisy load her purchase into her brother's small car, a classificatory sister who had been sitting on the grass across from the store approached her and requested

4 To protect privacy, all names are pseudonyms. 
a share of her purchases. Daisy reached into her bag and withdrew a couple of loaves of bread and a kilogram of meat. Once her 'sister' had departed, Daisy complained that too often she was asked to donate food to hungry relatives. She remarked that people should look after themselves instead of relying on her as a source of food. While demand sharing is the norm, requests that are perceived to be excessive often elicit complaints. These appeals for food, money or a lift into town are referred to as 'humbug' (cf. Altman and Martin, this volume, for further discussion). A phrase that one hears often in Lajamanu and across the Northern Territory is 'too much humbug'.

Often the sole income of Lajamanu residents is government assistance payments. Correlating the average salary of a family of six with food prices, the NT Government Department of Health and Community Services (2003: 9) estimates that 35 per cent of household money is spent on food from the store, but some researchers disagree with this figure, arguing that it is much higher (Scrimgeour et al. 1997: 38). Comparing the cost of foods at the Lajamanu store with that at the supermarket in Katherine, items such as white sugar and cordial-both popular items - cost almost twice as much in Lajamanu, while fresh broccoli was well more than twice as much per kilogram. Aboriginal people will spend a greater percentage of their income on meals than non-Aboriginal Australians. ${ }^{5}$ The combination of low income and high food prices motivates many Lajamanu residents to attempt to avoid demand sharing whenever possible. The desire to escape giving away substantial portions of purchased food affects spending choices.

Aside from restocking empty pantries, shopping on the day that money is received is one strategy for reducing demands for food. As other members of the community are being paid as well, it is assumed that fewer people will be asking for food and shoppers will be able to return home with a larger amount of their purchases. In addition to choosing days and times when it is believed fewer people will be demanding food, shopping trips are ideally kept to a minimum. When money is received, residents purchase as much as possible, concealing the food in a secure location at their home. In a further attempt to prevent losing a meal, and the money it took to purchase it, provisions are consumed rapidly. Expensive or particularly sought after items, such as fresh fruit, are eaten almost immediately, for fear that others will appropriate them. These strategies further reinforce the fortnightly pattern of feast and famine.

The poor condition of many homes in the community also influences the way in which food is purchased and consumed. Very few houses possessed locks

5 In addition to spending large amounts of money on food, Aboriginal people also spend a great deal of their income on cigarettes and alcohol. The sale and consumption of alcohol are prohibited in Lajamanu, forcing individuals wishing to purchase a beer to drive at least $300 \mathrm{~km}$. 
and could easily be accessed by kin while the inhabitants were away. Residents were concerned that if they left their homes unattended even for a brief period, hungry relatives would take their food. Preparing and cooking foods presented additional challenges. Many homes in Lajamanu lack a working stove, oven, or both. A survey of 3906 Aboriginal homes in the Northern Territory found that only 38 per cent had facilities that would allow residents to effectively prepare food in the house, such as stoves, ovens, water taps and locations to process and store food (Bailie and Runcie 2001: 366). Without cooking facilities in the home, preparing food entails building a fire and cooking outside, or using a functioning oven or stove at a relative's house. Both of these options often require reciprocity. Passers-by might demand a share of the clearly visible food, or relatives might expect to be fed because their cooking apparatus is being used.

One strategy to circumvent a lack of cooking facilities is to purchase prepared foods from the takeaway. Lying adjacent to the main store, the takeaway serves typical Australian fast food such as sandwiches, chips, meat pies, chicken wings, hamburgers, small pizzas, dim sims and candy as well as healthier options such as rice and vegetables, kangaroo stew, sandwiches and salads. The takeaway is an extremely popular source of food both in Lajamanu and other Aboriginal communities across the Northern Territory. Research shows that in some communities 69 per cent of all food transactions occur at the takeaway (Rowse et al. 1994: 64). Unlike the store, where shoppers spend large amounts of money during a single visit, at the takeaway, patrons usually purchase only a single meal, which is consumed immediately. Whereas shoppers exiting the store are often carrying large boxes of clearly visible food, people leaving the takeaway possess only a small bag or two. Furthermore, the exit from the takeaway is to the side of the shop, away from where people congregate. In addition, buying pre-cooked food eliminates the need for functional stoves and secure storage facilities. The meal can be concealed and eaten later in private, reducing the chances that other family members will request a share. Consequently, purchasing food from the takeaway, one is more likely to avoid demands..

The dynamics of food consumption in Lajamanu not only contextualise the continuing high rates of chronic illness that pervade Aboriginal communities, they also draw attention to the ways in which government-controlled payments, the enactment of sociality and bodily experience work together to structure daily life. On the one hand, the search for, and exchange of, food is also motivated by the physical imperative of hunger; during 'my low week', individuals endure empty stomachs. On the other hand, while the fortnightly cycle of payments constrains personal incomes, these monies are used to establish and maintain sociality. As Peterson (1999) notes, welfare monies allow Aboriginal individuals to perform relationships through demand sharing. After first arriving in 
Lajamanu, I discovered that exchanging food and other resources acted as an effective method of introduction. My relationships with many members of the community were first established in this way. Consequently, food has not only nutritional value; it also has social value. Food is a nexus through which physical, social and political bodies converge.

\section{Conclusion}

Food distribution has structured relations between peoples in central Australia and continues to exert a profound influence on the articulation of ethnic boundaries as well as the health of Warlpiri people. Although the Australian Government no longer espouses a policy of assimilation, apprehension over the way in which Aboriginal people in the Northern Territory access and use welfare payments has not ceased. In 2007, the Howard government instituted the Northern Territory National Emergency Response, which was justified, in part, as a response to the continued poor health and malnutrition of Aboriginal children. The intervention mandated that a significant portion of welfare payments be placed into managed accounts from which Aboriginal recipients were unable to withdraw cash. Instead, the money was to be spent on food purchased from the local shop. On a recent visit to Lajamanu, residents pulled out their so-called 'basic cards' used at the shop and complained about the new policies. Several people told me that the Government had reinstituted rationing. Furthermore, the new policy was seen as a further attempt at assimilation. One woman commented that the Government wished to control the money that Warlpiri people spent to curb the practice of demand sharing. She added that Warlpiri people would not allow their culture to be destroyed.

The consequences of welfare and rationing are visible not only in political narratives. While rationing might not have led to assimilation, it did bequeath a preference for certain non-local foods. White flour, processed sugar and tea became 'proper food' that people were accustomed to consuming. After the integration of Aboriginal people into the cash economy of the Northern Territory, these foods were purchased from local shops. Most money used to buy commercial foods was, however, obtained from welfare payments. Given the low income of many households and the high cost of purchasing food in Aboriginal communities, demand sharing is not only an important feature of Warlpiri sociality, it also impacts on health. To avoid reciprocity, individuals shop strategically. One way of doing this is by patronising the takeaway. Data confirm that the majority of the food purchased from community takeaways is not shared (Scrimgeour et al. 1997: 38). The pragmatics of low income, norms of reciprocity and poorly maintained homes with limited security and functional cooking facilities motivates meal choices. Takeaway food is easier to conceal, 
can be eaten immediately and does not need to be prepared. Unfortunately, prepared food from the takeaway generally has higher levels of fat, sugar and salt. The combination of welfare, high prices and demand sharing constrains food choice and, ultimately, health.

Following Peterson's challenge to present a more nuanced view of the Indigenous use of government assistance, it is important to examine the ways in which cash and other resources are distributed among Aboriginal people within the confines of everyday life. The high rates of morbidity, chronic lifestyle disease, obesity and malnutrition that are endured by Aboriginal people across the Northern Territory are influenced by historical, political, economic and social contexts. The confluence of government programs such as rationing and welfare with the everyday tactics of poverty and Warlpiri norms of reciprocity structures food choice and, as a result, nutrition. Consequently, if health outcomes are to improve, it will take more than just nutritional education campaigns or managed cash accounts.

\section{Acknowledgment}

This research was funded by the Australian Institute of Aboriginal and Torres Strait Islander Studies.

\section{References}

Australian Bureau of Statistics 2006. National Aboriginal and Torres Strait Islander Health Survey 2004-05, Northern Territory. Canberra: Australian Bureau of Statistics.

Bailie, R. and M. Runcie, 2001. Household infrastructure in Aboriginal communities and the implications for health improvement. Medical Journal of Australia 175: 363-6.

Food and Nutrition Unit 1998. Survey of Northern Territory Remote Community Stores. Darwin: Territory Health Services.

Harrison, L. 1991. Food, nutrition and growth in Aboriginal communities. In J. Reid (ed.) The Health of Aboriginal Australia, pp. 123-72. Marrickville, NSW: Harcourt Brace Jovanovich.

Hoy, W. E., S. Kondalsamy-Chennakesavan, Z. Wang, E. Briganti, J. Shaw, K. Polkinghorne and S. Chadban, 2007. Quantifying the excess risk for proteinuria, hypertension and diabetes in Australian Aborigines: comparison 
of profiles in three remote communities in the Northern Territory with those in the AusDiab study. Australian and New Zealand Journal of Public Health 31: 177-83.

Latz, P. 1995. Bushfires and Bushtucker: Aboriginal Plant Use in Central Australia. Alice Springs: IAD Press.

May, D. 1994. Aboriginal Labour and the Cattle Industry: Queensland from White Settlement to the Present. Cambridge: Cambridge University Press.

Musharbash, Y. 2004. Red bucket for the red cordial, green bucket for the green cordial: on the logic and logistics of Warlpiri birthday parties. Australian Journal of Anthropology 15: 12-22.

Naughton, J., K. O'Dea and A. Sinclair, 1986. Animal foods in traditional Aboriginal diets: polyunsaturated and low in fat. Lipids 21: 684-90.

Northern Territory Department of Health and Community Services 1995. Food for Thought in Rural Aboriginal Communities: An Information Booklet for Remote Northern Territory Store Managers. Darwin: Northern Territory Department of Health and Community Services.

Northern Territory Department of Health and Community Services 2003. Market Basket Survey of Remote Community Stores in the Northern Territory, April-June 2003. Darwin: Northern Territory Department of Health and Community Services.

O'Dea, K. 1985. Relationship between lifestyle-changes and health in Aborigines. In K. Larkins, D. McDonald and C. Watson (eds), Alcohol and Drug Use in a Changing Society: Proceedings of the 2nd National Drug Institute, Darwin, Northern Territory, Australia, 1985, pp. 96-102. Canberra: National Drug Institute.

Paine, R. 1977. The path to welfare colonialism. In R. Paine (ed.) The White Arctic: Anthropological Essays on Tutelage and Ethnicity, pp. 3-28. St John: Memorial University of Newfoundland.

Peterson, N. 1991. Cash, commoditisation and authenticity: when do Aboriginal people stop being hunter-gatherers. In N. Peterson and T. Matsuyama (eds), Cash, Commoditisation and Changing Foragers, pp. 67-90. Osaka: National Museum of Ethnology.

Peterson, N. 1993. Demand sharing: reciprocity and the pressure for generosity among foragers. American Anthropologist 95: 860-74. 
Peterson, N. 1998. Welfare colonialism and citizenship: politics, economics and agency. In N. Peterson and W. Sanders (eds), Citizenship and Indigenous Australians, pp. 101-17. Cambridge: Cambridge University Press.

Peterson, N. 1999. Hunter-gatherers in first world nation states: bringing anthropology home. Bulletin of the National Museum of Ethnology 23: 847-61.

Peterson, N., P. McConvell, S. Wild and R. Hagen, 1978. A Claim to Areas of Traditional Land by the Warlpiri and Kartangarurru-Kurintji. Alice Springs: Central Land Council.

Rowse, T. 1998. White Flour, White Power: From Rations to Citizenship in Central Australia. Cambridge: Cambridge University Press.

Rowse, T., D. Scrimgeour, S. Knight and D. Thomas, 1994. Food-purchasing behaviour in an Aboriginal community: 1: results of a survey. Australian Journal of Public Health 18: 63-6.

Russell, B. J., A. V. White, J. Newbury, C. Hattch, J. Thurley and A. B. Chang, 2004. Evaluation of hospitalisation for Indigenous children with malnutrition living in central Australia. Australian Journal of Rural Health 12: 187-91.

Scrimgeour, D., T. Rowse and A. Lucas, 1997. Too Much Sweet: The Social Relations of Diabetes in Central Australia. Darwin: Menzies School of Health Research.

Sharp, I. 1966. Report on the present wage position of Aborigines in the Northern Territory. In I. Sharp and C. M. Tatz (eds), Aborigines in the Economy, pp. 145-73. Brisbane: Jacaranda Press.

Stewart, I. 1997. Research into the Cost, Availability and Preferences for Fresh Food Compared with Convenience Food. Australia: Roy Morgan Research Centre.

Wright, J. 1981. The Cry for the Dead. Oxford: Oxford University Press.

Zhao, Y. and K. Dempsey, 2006. Causes of inequality in life expectancy between Indigenous and non-Indigenous people in the Northern Territory, 19812000: a decomposition analysis. Medical Journal of Australia 184: 490-4.

Zhao, Y., C. Connors, J. Wright, S. Guthridge and R. Bailie, 2008. Estimating chronic disease prevalence among the remote Aboriginal population of the Northern Territory using multiple data sources. Australian and New Zealand Journal of Public Health 32: 307-13. 